VV.AA. José Maurício de Carvalho, Org. VII Colóquio Antero de Quental: Pensamento, Experiência e Formas Políticas em Portugal e no Brasil (séculos XIX e XX). São João del Rey e Lisboa: UFSJ e Instituto de Filosofia Luso-Brasileiro, 11 a 16 de setembro de 2006.

José Beluci Caporalini*

A Universidade Federal de São João del-Rey - UFSJ e o Instituto de Filosofia Luso-Brasileiro - Lisboa realizaram dos dias 11 a 16 de setembro de 2006 o colóquio acima mencionado. Nele foi apresentada uma série de conferências, agora em artigos, nas quais os diversos autores procuram dar uma idéia do que se passou no Brasil e em Portugal no campo do pensamento e da prática política nos séculos XIX e XX e cujas características principais abaixo se apresentam.

Há, no livro de ATAS, do referido colóquio vinte quatro artigos e uma resenha.

No primeiro artigo do mesmo, de autoria do Prof. Dr. José Maurício de Carvalho, Coordenador do Colóquio e professor da UFSJ, intitulado O liberalismo de John Locke e Silvestre Pinheiro Ferreira, o autor fala sobre as formulações iniciais do liberalismo nos mundos britânico e luso-brasileiro e procura indicar proximidades e divergências das duas formulações. John Locke e Pinheiro Ferreira são os liberais da primeira hora, tomados para representar os dois contextos. Apesar de Silvestre tentar acompanhar Locke, as suas idéias não são como as dos seguidores britânicos do filósofo empirista, mas guardam singularidade, na hipótese de José Maurício, devido à peculiar tradição cultural em que se situava.

* Doutor em Filosofia pela Universidade Gama Filho e Professor de Filosofia do DCS da Universidade Estadual de Maringá. E-mail: jcaporalini@hotmail.com 
No artigo Pensamento político em Portugal no século XIX, de José Esteves Pereira, professor da Universidade Nova de Lisboa, ele procura caracterizar as principais vias do pensamento político em Portugal no decorrer do século XIX. Examina, inicialmente, o liberalismo e os seus antecedentes culturais e políticos, sua afirmação a partir da Revolução de 1820 (Vintismo) até ao termo da vigência da Carta Constitucional outorgada por D. Pedro IV, em 1826. Estuda as diferentes correntes liberais, que denomina radical, gradualista e moderada, bem como o fundo tradicionalista regenerador que as atravessa. Em seguida, diferencia o sentido político e social do liberalismo. Examina igualmente outra linha de pensamento, de feição tradicionalista, que é estudada atendendo não apenas à sua orientação contra-revolucionária, mas também à importância que assumiu, a partir de meados do século, como vetor de reação ao liberalismo individualista e como motor de reformulação dos valores sociais anti-revolucionários e orgânicos.

No artigo Kratos e Bia - Patrimonialismo e Barbárie na República Argentina, Alexandro Ferreira de Souza, aluno de Pós-Graduação da UFJF parte da vida na Grécia Antiga para tratar do Pampa argentino. Ele mostra como o patrimonialismo caudilhista se fez presente na formação da República Argentina. Para realizar tal projeto, comenta o livro Facundo: civilização e barbárie no pampa argentino, de Domingo Faustino Sarmiento (1881-1888).

António Pedro Mesquita, professor da Universidade de Lisboa, em seu artigo Os projetos de reformismo tradicionalista em Portugal no primeiro período contra-revolucionário (1823-1826) examina as ações de D. João VI quando revogou a Constituição Liberal de 1822. Ele afirma que, para o monarca ela era contraditória com o princípio monárquico que aparentemente consagrava e incompatível com as tradições lusitanas. O rei nomeia então uma Junta encarregada de elaborar um projeto de Lei Fundamental do Reino. São os fatos em torno à Junta o tema deste trabalho.

Wlamir José da Silva, professor da UFSJ, em seu artigo $O$ protótipo dos toucinheiros: a cultura política moderada na primeira metade dos Oitocentos afirma que a construção de uma visão política

Educ. e Filos., Uberlândia, v. 22, n. 44, p. 227-236, jul./dez. 2008. 
liberal-moderada na Província de Minas Gerais na primeira metade do século XIX foi obra de uma elite orgânica. Essa elite moderada elaborou um protótipo de Estado nacional que, ainda que derrotado, influiu na trajetória de formação política do Brasil e é um objeto significativo para a nossa compreensão desse momento histórico.

Adelmo José da Silva, professor da UFSJ, em seu artigo $O$ pensamento positivista de João Pinheiro da Silva, explica que no último quartel do século passado assistia-se no Brasil à decadência da escola eclética e, conseqüentemente, das teses que sustentavam o Império Constitucional de D. Pedro II. Duas escolas novas irão aparecer a partir da década de 70 no cenário intelectual brasileiro: o Positivismo e o Culturalismo. Adelmo examina o papel assumido pelo positivista João Pinheiro para o desenvolvimento das idéias políticas no Brasil naquele momento.

Manuel Felipe Canavieira, professor da Universidade Nova de Lisboa, em seu artigo $O$ anti-semitismo no pensamento do integralista brasileiro Gustavo Barroso examina a obra do referido pensador, cujo título é O quarto império e Brasil-Colônia de banqueiros. Afirma que era um antigo interesse estudar o pensamento de Barroso. É à análise dos dois volumes da obra a tarefa a que se dedica no Colóquio.

Ernesto Castro Leal, professor da Universidade de Lisboa, em seu artigo Bases organicistas e federalistas no pensamento federalista republicano português (1910-1926) analisa a emergência de propostas federalistas em Portugal, entre a revolução de Outubro de 1910 e a revolução de Maio de 1926, que foram influenciadas por idéias políticas européias e americanas. Fizeram parte do processo cultural publicistas que propuseram variados projetos de República. Essencialmente, manifestou-se uma corrente plural de crítica a aspectos centralistas do poder republicano e afirmou-se com algum significado a dinâmica do ideário não-centralizado, municipalista e provincialista.

José Maurício de Carvalho em seu segundo artigo, intitulado A persistência da proposta liberal no período entre guerras, a formulação de Tancredo Neves, procura mostrar que Tancredo marcou a história 
do Brasil durante o século XX. Foi um hábil e prático negociador, mas tinha idéias bem meditadas sobre a vida e os valores humanos, a organização social, a cultura e o futuro do povo brasileiro. A atuação política de Tancredo se baseou nessas idéias e ele foi fiel aos eixos centrais do liberalismo social que pensou nos anos trinta e quarenta, quando ainda não era reconhecido como importante figura da República. Ele elaborou uma teoria liberal com forte preocupação social, na qual o Estado tinha papel importante no desenvolvimento nacional, atuando em campos como educação, saúde, segurança e setores estratégicos da economia. Suas reflexões e práticas políticas são exemplos de que o pensamento liberal se manteve no cenário nacional, mesmo em períodos francamente desfavoráveis como durante o governo revolucionário de Vargas e, em especial, durante o Estado Novo.

Francisco Martins de Souza, da Academia Brasileira de Filosofia, em seu artigo A Revolução Industrial sob a égide do Estado Novo e o corporativismo brasileiro faz uma breve indicação de como foi organizada a ideologia do Estado Condutor. Para ele, Francisco Campos foi o principal articulador da Nova Ordem, pois promoveu a Reforma do Ensino, criou a Universidade do Brasil, estabeleceu as bases da Democracia Orgânica Corporativista e elaborou a Carta Constitucional de 1937 para fixar tal doutrina.

O professor Fábio Rômulo Reis, da UFSJ, em seu artigo $O$ pensamento político de Milton Campos, estuda a trajetória do liberalismo político brasileiro formulado pelo político mineiro. Enfatiza sua contribuição filosófico-política para a cultura brasileira. O problema fundamental de sua proposta liberal é de natureza ética. Ele entende que o Estado não pode ficar à margem do problema da justiça social. Seu ideário segue as vertentes de tradição mineira: a conciliação, a reserva, o recato e, sobretudo, o apego ao Estado de Direito e à ordem constitucional.

O professor Aquiles Côrtes Guimarães, em seu artigo A crise da consciência política na primeira metade do século XX, mostra que ela foi tão intensa quanto aquela que marcou o século XIX e que resultou das guerras napoleônicas. Cada século tem suas marcas nas realizações políticas. Ele estende sua reflexão para assinalar

Educ. e Filos., Uberlândia, v. 22, n. 44, p. 227-236, jul./dez. 2008. 
que o século XX experimentou uma profunda crise de cultura que permeou a efervescência bélica e revolucionária daquela época.

A professora Anna Maria Moog Rodrigues, da Academia Brasileira de Filosofia, em seu artigo A liderança católica no centro Dom Vital em meados do século XX, procura esclarecer que esse trabalho é parte da pesquisa que faz do pensamento político católico no Brasil. Seu propósito é examinar o pensamento de dois representantes da liderança católica nas décadas de 40,50 e 60 do século passado, Alceu Amoroso Lima (1893-1983) e Gustavo Corção (1896-1978). Ela aborda a unidade do pensamento político e da militância de ambos no Centro D. Vital e termina falando do que os afastou.

O professor António Braz Teixeira, da Universidade Autônoma de Lisboa, apresenta o seu trabalho denominado Conceitos e formas da democracia na primeira metade do século XX em Portugal, no qual afirma que as posições doutrinárias sobre o assunto dividem-se entre os que, como Raúl Proença (1884-1941), António Sérgio (18831969), Leonardo Coimbra (1883-1936), Sant'Anna Dionísio (19021991), José Marinho (1904-1975) e Augusto Saraiva (1900-1975), assumem a posição liberal presente na Constituição de 1911, dando-lhe dimensão diversa do positivismo que marcou o pensamento republicano de Outubro de 1910, e as dos que criticavam e recusavam esse mesmo republicanismo, seja propondo uma nova doutrina democrática, como aconteceu com o grupo da Renovação Democrática, seja procurando demonstrar as contradições e as insuficiências do pensamento democrático e liberal, como Cabral de Moncada (1888-1974), seja contrapondo à visão individualista e republicana da democracia liberal a idéia de "democracia orgânica", como propugnaram tanto o Integralismo Lusitano como os defensores do Estado Novo, desde Salazar a Quirino de Jesus ou Marcelo Caetano.

Antônio Paim, do Instituto de Filosofia, em seu artigo Ausência de socialismo democrático no Brasil, considera que o marxismo divulgado e predominante no Brasil é uma versão de inspiração positivista, e é essa a razão pela qual o autoritarismo republicano executado pelos positivistas republicanos foi passado aos socialistas 
brasileiros. Essa versão positivista do marxismo acha-se suficientemente caracterizada nos seus livros História das idéias filosóficas no Brasil (5.ed de 1997) e Escola cientificista brasileira (2002). Paim afirma que, se analisarmos a elaboração teórica organizada pelos intelectuais do PT, pode-se verificar que é grande a lista das teses atribuídas a Marx, que, na verdade, provêm de Comte. Assim, parcela substancial dos defensores das propostas do marxismoleninismo apresenta teses postas em circulação pelos positivistas brasileiros. A sua análise do que se passou em Portugal, mostra que, do mesmo modo que ocorreu lá, também no Brasil poderemos construir partidos socialistas que se afastam dessa inspiração positivista.

O professor Ubiratan Borges de Macedo, da Universidade Gama Filho, em seu trabalho denominado $O$ integralismo em Portugal e no Brasil, expõe um histórico da evolução do Integralismo nos dois países. Ele mostra como a formação política do Estado Novo com maior apoio da sociedade afastou e marginalizou os dois integralismos. Aponta, em seguida, os caracteres diferenciais dos dois movimentos: o lusitano é monárquico, de quadros e suprapartidários; o brasileiro é um movimento republicano e partido de massas. Finalmente, revela os aspectos comuns de seus ideários.

Já em seu outro artigo o Liberalismo na segunda metade do século XX no Brasil, ele menciona o reaparecimento das idéias liberais depois da II Guerra Mundial, pois, no período entre as duas grandes guerras, o liberalismo foi tido como projeto superado. A experiência totalitária experimentada entre os anos 30 e 40 facilitou seu renascimento, isto é, o autoritarismo ensejou a retomada da liberdade. Em sua conferência, Ubiratan fornece os momentos marcantes da evolução do liberalismo nas últimas décadas. Para recuperá-la teórica e institucionalmente, diz que contribuíram: Karl Popper, Raymond Aron, Michael Polany e Hans Barth. No período seguinte (1947 a 1961) assiste-se a uma recuperação da herança liberal. Os autores mais importantes desse momento são: Hayek, Popper, Aron e a romancista Ayn Rand. No momento seguinte (1861 a 1889), vive-se o apogeu da sistematização liberal. Grandes

Educ. e Filos., Uberlândia, v. 22, n. 44, p. 227-236, jul./dez. 2008. 
obras teóricas apresentam as teses filosóficas, políticas e econômicas do liberalismo. Hayek, com os Fundamentos da Liberdade e a trilogia Direito, Legislação e Liberdade, e Rawls, com o livro a Teoria da Justiça, são os autores que ele avalia como os mais importantes, mas ele também menciona R. Nozick, R. Dworkin, J. Buchanan ou Murray Rothbard. Macedo entende que se pode agrupar os liberais em três escolas: os neoliberais ou liberais clássicos, com Hayek e von Mises, os libertários ou anarco-capitalistas, como Nozick, Rothbard e David Friedmann e os denominados sociais-liberais - em que se destacam Aron, Rawls, Dworkin, Ralph Dahrendorf. É o momento em que o prestígio das teses liberais é enorme. Nos últimos anos assiste-se ao surgimento de uma outra fase. Vive-se um momento de avaliação crítica das experiências liberais. John Gray escreve um Post Liberalism (1993), no qual discute o que está vivo e morto no liberalismo e, em livros posteriores, abandona o liberalismo rumando para o comunistarismo.

Arsênio Eduardo Corrêa, do Instituto Brasileiro de Filosofia, em seu artigo Dois modelos de abertura politica, examina o processo de abertura democrática em Portugal e no Brasil, traçando um paralelo e apontando pontos de convergência e divergência. Ele explica que o processo de abertura democrática ocorrida nos últimos anos foi diferente no Brasil e em Portugal. No Brasil encaminhou-se pacificamente; em Portugal, valeu-se das armas. No Brasil, o objetivo era afastar os militares do poder; em Portugal, ao contrário, os militares chegaram ao poder durante esse processo. Parece, a Arsênio, que, nos dois países, prevaleceu, afinal, o elemento moderado. Pode-se dizer que, no Brasil, os militares tendiam para a direita e, em Portugal, para a esquerda, mas havia algo comum entre eles: o desapreço pelo sistema representativo e a desconfiança em relação ao capitalismo.

O professor Paulo César de Oliveira, da UFSJ, em seu artigo $A$ sociedade fechada e a cultura democrática no Brasil, resume a análise de Paulo Freire sobre a transição política pela qual passou o Brasil nas décadas de 60, 70 e 80 do século XX. Em sua análise, usa categorias como: sociedade fechada, sociedade em abertura e cultura do silêncio. Ele entende que esse período tem raízes na 
história brasileira e que, simultânea e paradoxalmente, apresenta tanto o risco de agravamento da situação de dependência colonial, reduzindo o homem a objeto de comando de pequena elite, como a perspectivas de mudança, com a edificação da autonomia do homem e da sociedade brasileira.

O professor Paulo Ferreira da Cunha, da Universidade do Porto, em seu artigo O espectro político - ideológico português contemporâneo: tradições, assimetrias e paradoxos (1974-2006) resume o que se passou em Portugal depois da Revolução de 74. Afirma que, nos anos sessenta e início dos setenta, floresciam nas universidades portuguesas todas as tonalidades de marxismoleninismo, embora proibidas. Contrastadas apenas por pequenos nichos situacionistas, algumas resistências tradicionalistas, monárquicas e incipientes aspirações de esquerda e direita, democráticas, que, contudo, se integravam nas duas grandes frentes (situação e oposição), de um lado e do outro. No Parlamento, uma incipiente ala liberal não conseguia sequer ser oposição tolerada, nem tinha consistência ideológica própria: acabaria por resignar. A revolução do 25 de Abril veio permitir a manifestação das mais diferentes ideologias. Mesmo assim, a liberdade não seria plena. Logo se ilegalizaram partidos de direita e se impediu a ida às urnas de maoístas e de um partido democrata-cristão (PDC). A Constituição foi previamente pactuada entre os militares (MFA) e os principais partidos. Mas uma vez reentrado na ordem plenamente democrática, Portugal herdou um sistema partidário enviesado, em que a direita continua teoricamente a terminar no centro, e em que só os extremos se atrevem a ter um discurso ideológico. Domina o revezamento, em que ao centro-esquerda socialista se tem sucedido o centro-direita "social-democrata", e vice-versa, ou, noutra perspectiva: é o reino do centrão, sem ideologia real.

O professor Ricardo Vélez Rodríguez, da UFJF, em seu artigo intitulado $O$ autoritarismo no contexto de uma visão crítica da evolução do pensamento republicano: uma abordagem da escola weberiana brasileira, discute o conceito de Patrimonialismo, estuda-o como proposta da escola weberiana e menciona as adaptações que sofreu

Educ. e Filos., Uberlândia, v. 22, n. 44, p. 227-236, jul./dez. 2008. 
para ser aplicado à realidade brasileira, explica a necessidade de estabelecer uma clara distinção entre o modelo weberiano puro e o Patrimonialismo Modernizador, que é o modelo consolidado no Brasil ao redor de um segmento do Estado Patrimonial, que se propõe ação modernizadora.

Leonardo Prota, do FACNOPAR e Instituto de Humanidades, parte da indagação sobre a dificuldade de consolidar as instituições do sistema representativo no Brasil e faz em seu artigo Sistema representativo no Brasil um paralelo entre a situação brasileira e a italiana antes do Risorgimento e da possível solução para o problema com base em ampla movimentação da sociedade.

Em seu segundo artigo o professor Ricardo Vélez Rodríguez, presta uma homenagem a Miguel Reale, a quem chama de o maior filósofo (sic!) contemporâneo brasileiro. Afirma que a filosofia de Miguel Reale fecundou de maneira indelével a tradição filosófica brasileira, de forma tal que, hoje, não se poderia pretender identificar a meditação nacional sem se fazer referência obrigatória a ele.

O professor Tiago Adão Lara, da UFJF, fez um balanço final sobre os objetivos e realizações do Colóquio.

\section{APRECIAÇÕES FINAIS}

Qual foi o propósito do VII Colóquio Antero de Quental, realizado entre os dias 11 e 16 de setembro de 2006 e promovido pela UFSJ e o Instituto de Filosofia Luso-Brasileiro? Dar continuidade às pesquisas já realizadas anteriormente e, agora, explorar o pensamento político luso-brasileiro, meditando sobre o pensamento, experiência e formas políticas em Portugal e no Brasil (Séculos XIX e XX).

No que se propôs, através de seus artigos e intervenções, o Colóquio desincumbiu-se perfeitamente. Intervenções inteligentes que mostram a seriedade e competência de seus autores.

O professor Antônio Paim, do Instituto de Filosofia, em seu artigo Ausência de socialismo democrático no Brasil, considera o marxismo divulgado e predominante no Brasil como uma versão 
de inspiração positivista, problema que já havia abordado em dois livros seus. Afirma que, se se analisar a elaboração teórica organizada pelos intelectuais do PT, pode-se verificar que é grande a lista das teses atribuídas a Marx, que, na verdade, provêm de Comte. É uma afirmação intelectualmente muito séria tendo-se em vista que alguns dos intelectuais em questão, independente de questão partidária, têm um grande peso intelectual. Será que eles não perceberam e não percebem o sério equívoco, em suas aulas, escritos, pesquisas? Por que é que só Paim neste país percebeu isto?

Uma pergunta ou outra, em relação ao Colóquio: se este Colóquio de Filosofia tivesse sido promovido por um Departamento de Sociologia ou mesmo de História faria muita diferença? É provável que não. Contudo, há que se louvar o esforço, o denodo profundo e sério destes intelectuais que procuraram levantar pacientemente elementos filosóficos lá onde outras pessoas não os encontrariam, por preconceito ou mesmo desatenção. Trata-se, claro está, de um trabalho mais que profícuo por aquilo que os seus expositores já têm demonstrado ao longo destes anos.

Outra coisa que é afirmada, ainda que en passant: que Miguel Reale é o maior filósofo brasileiro falecido há pouco: e o Pe. Vaz, maior autoridade mundial em seus dias, para muitos, em Hegel, como fica? Ele também era pensador, brasileiro, só que seu interesse filosófico e especulativo era outro. Não se pode validamente ignorálo, uma vez que, em sua área, era, ao menos tão grande quanto Reale. 